\title{
Adsorption and Separation of Chromium from Electroplating wastewater with Banana Stem Adsorbent
}

\author{
Shaohong Peng ${ }^{1, a}$ and Liwang Jiang ${ }^{1, b}$ \\ ${ }^{1}$ Guangdong University of Petrochemical Technology, Technology Research Center for \\ Petrochemical Resources Clean Utilization of Guangdong Province, Maoming 52500, China。
}

ashpeng@gdupt.edu.cn,b1159768864@qq.com

Keywords: banana stem adsorbent; chromium; Electroplating wastewater.

Abstract. The preparation process of waste banana stem adsorbent and the conditions of removing $\mathrm{Cr}$ were studied. The experiment results showed that the saturated adsorption capacity of banana stem adsorbent with phosphoric acid reached $5.84 \mathrm{mg} / \mathrm{g}$, over $95 \%$ of $\mathrm{Cr}(\mathrm{VI})$ and $70 \%$ of total $\mathrm{Cr}$ can be removed from water with banana stem adsorbent at $20 \sim 30{ }^{\circ} \mathrm{C}$ and $\mathrm{pH}=2 \sim 3$. When used for cleaning model electroplating wastewater, it was found that the removal effect of $\mathrm{Cr}$ with banana stem adsorbent was apparently higher than the commercial activated carbon. The concentration of heavy metals can meet the emission standard of electroplating wastewater after treated with banana stem adsorbent.

\section{Introduction}

Banana is the most popular fruit, because a banana tree can only grow one ear of fruit, so the waste banana trees were always produced with the harvest of banana, and the weight of waste banana trees were almost equal to the weight of banana. At present, these waste banana trees were mainly discarded in the field randomly, it often take a very long time for corrosion and degradation of banana trees under natural conditions, the process will not only pollute environment, but also cause serious insect pest. On the other hand, banana trees are also valuable resource containing natural fiber, which have been widely used for paper industry, spinning, polymer reinforcing material[1]. Nevertheless, the recycling of banana in these fields requires complicated technologies and equipment, so their industrial applications were greatly limited in past time. Recently, research on preparation of low-cost wastewater cleaning agent with agricultural and forest wastes has become an important development direction of high-efficiency utilization of agricultural and forest wastes. Various agricultural wastes[2], such as corn stalks, straw, wheat-straw and bagasse are most common raw materials preparing wastewater cleaning and adsorbing agents. Research[3] pointed out banana tree is mainly composed of cellulose, hemicellulose and lignin. Total content of these three components exceeds $90 \%$. Stem of banana trees is actual cauloid formed with multilayer tile-shaped sheath overlapping. It has loose and porous internal structure, so it is the ideal raw material to prepare adsorbing materials. In this study, preparations of adsorbent with banana trees were studied and its effect in processing electroplate discharged wastewater was studied.

\section{Materials and Methods}

Leaves were removed from banana stems. After most water was eliminated by an extractor, further was dried for $2 \mathrm{~h}$ at $105^{\circ} \mathrm{C}$, and then grinded into particles (diameter $<0.1 \mathrm{~mm}$ ), the model electroplating wastewater used in this study was prepared according the composition of real electroplate discharged wastewater. All reagents used in this study were analytical pure.

$50 \mathrm{~g}$ of banana stem powder was put into a beaker and reacted with aqueous solution of modifier for $24 \mathrm{~h}$. then powder were filtered and rinsed to neural with distilled water, finally dried for $2 \mathrm{~h}$ at $105^{\circ} \mathrm{C}$, banana stem adsorbent was prepared. .

$10 \mathrm{~g}$ of banana stem adsorbent was put in a $250 \mathrm{ml}$ conical flask, then $100 \mathrm{~mL}$ water containing $\mathrm{Cr}(\mathrm{VI})$ was also added and the mixture was oscillated in thermostatic waterbath for $2 \mathrm{~h}$. According to 
GB7467-87 and GB7466-87, Cr(VI) and total Cr concentration in the aqueous solution were tested by the color rendering method of diphenyl carbonyl dihydrazide.

\section{Results and Discussions}

\section{Preparation of Adsorbent}

The banana stem adsorbent unmodified was applied directly to adsorb metal ions. It is not only has a smaller adsorption capacity, but also pectin, humic acid and lignin in banana stem are easy to be dissolved into water, thus deepening the water color and increasing organic concentration, this will cause secondary pollution. Modifiers like acid, alkali and amine can facilitate crosslinking, stabilization and functionalization of adsorbent, thus improving the adsorption performance. Processing effects of different chemical modifiers are shown in Table 1.

Table 1 Modified experimental results of banana stem-based adsorbent

\begin{tabular}{cccccc}
\hline Modifiers & $\begin{array}{c}\text { Phosphoric } \\
\text { acid }\end{array}$ & $\begin{array}{c}\text { Sulfuric } \\
\text { acid }\end{array}$ & $\begin{array}{c}\text { Nitric } \\
\text { acid }\end{array}$ & Ethylenediamine & $\begin{array}{c}\text { Sodium } \\
\text { hydroxide }\end{array}$ \\
\hline $\begin{array}{c}\text { Growth rate of adsorption } \\
\text { capacity [\%] }\end{array}$ & 22.54 & 13.32 & 8.06 & 6.78 & 12.43 \\
$\begin{array}{c}\text { Dissolving of color } \\
\text { components }\end{array}$ & Few & Few & Few & Many & Many \\
\hline
\end{tabular}

Experimental results demonstrated that after processed by $0.10 \mathrm{~mol} / \mathrm{L}$ phosphoric acid, sulfuric acid, nitric acid or $1.00 \%$ sodium hydroxide and ethylenediamine, the adsorpton capacity of adsorbent is increased obviously. Among them, phosphoric acid has the best effect. Dissolving content of color components declines dramatically and stability is enhanced sharply. Therefore, phosphoric acid is a relatively appropriate modifier. $0.1 \mathrm{~mol} / \mathrm{L}$ phosphoric acid and solid-to-liquid ratio was $1: 5$.The isothermal adsorption curve of banana stem adsorbent at $25^{\circ} \mathrm{C}$ is shown in Fig.2.

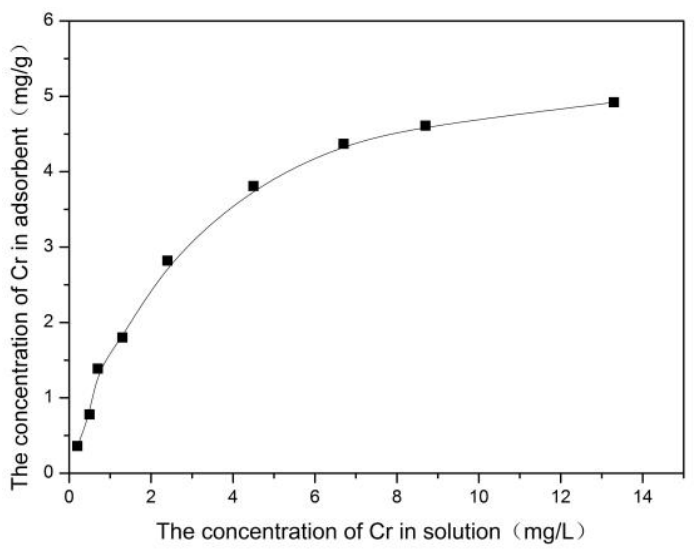

Fig.1 Isothermal adsorption curve of adsorbent $\left(25^{\circ} \mathrm{C}\right)$

According to experimental results (Fig.1), the isothermal adsorption curve of banana stem adsorbent agrees well with that of the first type. It can be calculated by following Langmuir equation[4]:

where.

$$
\frac{\mathrm{C}_{\mathrm{e}}}{\mathrm{q}_{\mathrm{e}}}=\frac{1}{\mathrm{Q}_{\mathrm{m}} \times \mathrm{b}}+\frac{\mathrm{C}_{\mathrm{e}}}{\mathrm{Q}_{\mathrm{m}}}
$$

$\mathrm{q}_{\mathrm{e}}$ is equilibrium adsorption capacity $(\mathrm{mg} / \mathrm{g})$,

$\mathrm{c}_{\mathrm{e}}$ is equilibrium concentration $(\mathrm{mg} / \mathrm{L})$,

$\mathrm{Q}_{\mathrm{m}}$ is saturated adsorption capacity of monomolecular layer $(\mathrm{mg} / \mathrm{g})$.

A straight line of Ce was gained based on $\frac{C e}{Q m}$. It can be calculated from intercept $\left(\frac{1}{Q m} \times \frac{1}{b}\right)$ and slope $\left(\frac{1}{Q m}\right)$ of the straight line that $\mathrm{Q}_{\mathrm{m}}=4.89 \mathrm{mg} / \mathrm{g}, \mathrm{r}_{1}=0.97976$, and $\mathrm{q}_{\mathrm{e}}=5.84 \mathrm{mg} / \mathrm{g}$

\section{The effect of adsorption conditions on the removal rate of $\mathrm{Cr}$}

$\mathrm{pH}$ and temperature are main influencing factors on adsorption efficiency. In this experment, $10 \mathrm{~g}$ adsorbent and $100 \mathrm{~mL} 1 \mathrm{mg} / \mathrm{L} \mathrm{Cr}(\mathrm{VI})$ water were added into a $250 \mathrm{ml}$ conical flask. Solution $\mathrm{pH}$ was 
adjusted to the set value with $0.1 \mathrm{~mol} / \mathrm{L}$ sulfuric acid and $\mathrm{NaOH}$ solution. Next, the solution was oscillated in water bath at the set temperature for $2 \mathrm{~h}$. The experimental results of separating $\mathrm{Cr}$ from water are shown in Fig.2.
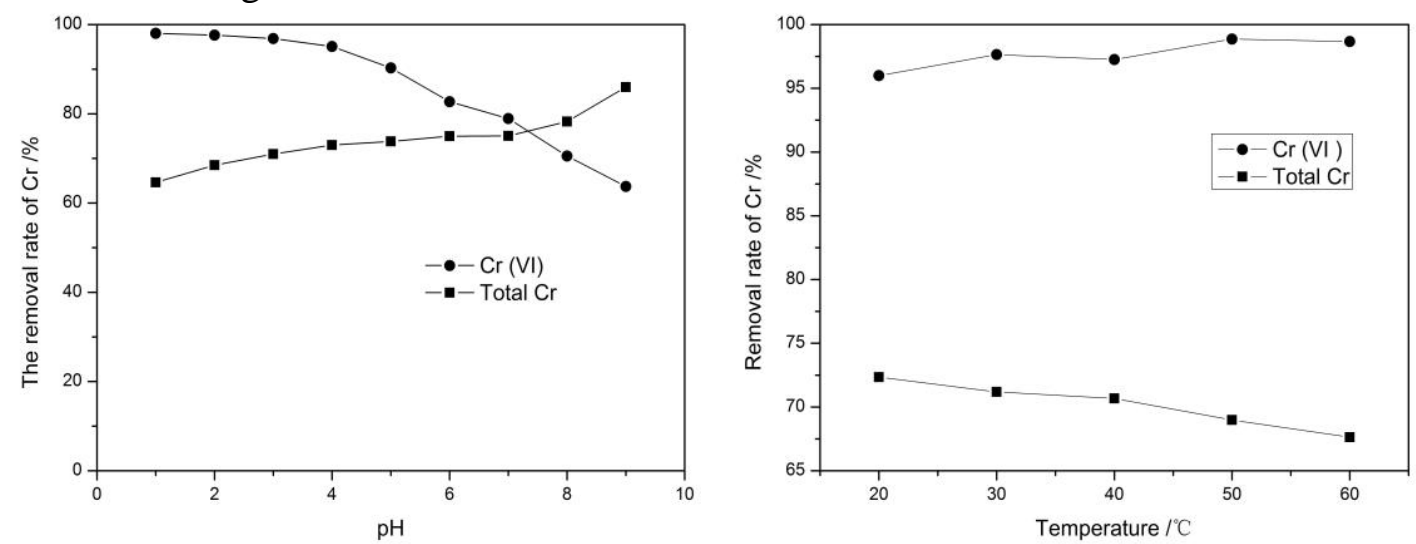

Fig.2 Influences of adsorption conditions on removal rate of $\mathrm{Cr}$

In Fig.2, it can be founded that $\mathrm{pH}$ can significantly influence the removal rate of $\mathrm{Cr}(\mathrm{VI})$. With the increase of $\mathrm{pH}$, the removal rate of $\mathrm{Cr}(\mathrm{VI})$ reduces quickly. This is mainly because most of $\mathrm{Cr}(\mathrm{VI})$ in solution exists as $\mathrm{HCrO}_{4}^{-}$under strong acid conditions, and $\mathrm{HCrO}_{4}{ }^{-}$can form covalent bonds with hydroxyls and carboxyls of the banana stem adsorbent, so it is a chemical adsorption process. As $\mathrm{pH}$ further increases, some of $\mathrm{HCrO}_{4}^{-}$will turn into $\mathrm{Cr}_{2} \mathrm{O}_{7}{ }^{2-}$, which has larger radius. The affinity between functional groups of adsorbent and $\mathrm{Cr}_{2} \mathrm{O}_{7}{ }^{2-}$ is weaker than that of affinity between functional groups of adsorbent and $\mathrm{OH}^{-}$, so reducing adsorption capacity of $\mathrm{Cr}(\mathrm{VI})$. Therefore, high $\mathrm{pH}$ is disadvantageous for removal of $\mathrm{Cr}$ (VI). The affects trend of temperature on the removal rate of $\mathrm{Cr}(\mathrm{VI})$ is different from $\mathrm{pH}$, the removal rate of $\mathrm{Cr}(\mathrm{VI})$ is positively related with temperature. The removal rate of $\mathrm{Cr}(\mathrm{VI})$ increases with temperature, but high temperature is generally unbeneficial of adsorption process, indicating that reduction of $\mathrm{Cr}$ (VI) concentration in aqueous solution is not only caused by adsorption of banana stem adsorbent.

By analyzing the concentration of total $\mathrm{Cr}$ and $\mathrm{Cr}^{3+}$ in adsorbed solution, it was found that the removal rate of $\mathrm{Cr}$ (VI) exceeds $98 \%$ and the removal rate of total $\mathrm{Cr}$ can only reach $60 \sim 70 \%$ under conditions of $\mathrm{pH}=2 \sim 3$ and at $30^{\circ} \mathrm{C}$. This reflects that reduction of some $\mathrm{Cr}$ (VI) in solution is not contributed by adsorbent, but is the consequence of conversion into $\mathrm{Cr}^{3+} \cdot \mathrm{Cr}^{3+}$ is are very difficult to form covalent bonds with adsorbent, it is separated by mainly ion exchange and physicl adsorption. Although low $\mathrm{pH}$ is beneficial for removal of $\mathrm{Cr}(\mathrm{VI})$, protonation of tannin in banana tree will occur if the acidity of solution is too high, which will weaken the static attractions between $\mathrm{Cr}^{3+}$ and adsorbent, and reduce ion exchange between tannin molecules and $\mathrm{Cr}^{3+}$. Therefore, $\mathrm{pH}=2 \sim 3$ is appropriate for adsorption separation of $\mathrm{Cr}(\mathrm{VI})$ and $\mathrm{Cr}^{3+}$. At the conditions, the removal rate of $\mathrm{Cr}(\mathrm{VI})$ reaches over $95 \%$ and the removal rate of total $\mathrm{Cr}$ is higher than $70 \%$. On the other hand, although high $\mathrm{pH}$ is disadvantangeous for adsorption separation of $\mathrm{Cr}(\mathrm{VI})$, it is conducive for $\mathrm{Cr}^{3+}$ to form precipitation of $\mathrm{Cr}(\mathrm{OH})_{3}$ with the increase of $\mathrm{OH}^{-}$concentration. Thus, $\mathrm{Cr}^{3+}$ can be removed by increasing $\mathrm{pH}$ of solution when there's few $\mathrm{Cr}(\mathrm{VI})$ amount.

Based on above analysis, $\mathrm{Cr}(\mathrm{VI})$ removal from water by banana stem absorbent includes two processes: one is adsoption separation through covalent bonds between anions (e.g. $\mathrm{HCrO}_{4}{ }^{-}$and $\mathrm{Cr}_{2} \mathrm{O}_{7}{ }^{2-}$ ) and functional groups of adsorbent. The other is $\mathrm{Cr}(\mathrm{VI})$ reduction into $\mathrm{Cr}^{3+}$ by reducibility matters in adsorbent. Since $\mathrm{Cr}^{3+}$ can't be adsorbed completely, some parts of them will stay in aqueous solution. Both processes are chemical exothermic process. Therefore, removal rate of $\mathrm{Cr}(\mathrm{VI})$ increases with the increase of temperature. Although $\mathrm{Cr}^{3+}$ toxicity is far lower than $\mathrm{Cr}(\mathrm{VI})$, it still remains quite high toxicity, so $\mathrm{Cr}^{3+}$ must also be removed from water as much as possible. According to experimental results on the effect of temperature and $\mathrm{pH}$ on removal rate, it is beneficial for removal of $\mathrm{Cr}(\mathrm{VI})$ at lower $\mathrm{pH}$ range and beneficial for precipitation separation of $\mathrm{Cr}^{3+}$ at higher $\mathrm{pH}$ range. Therefore, after adsorption separation under $20 \sim 30^{\circ} \mathrm{C}$ and $\mathrm{pH}=2 \sim 3$, followed by a precipitation, over $80 \%$ of total $\mathrm{Cr}$ and $95 \%$ of $\mathrm{Cr}(\mathrm{VI})$ can be successfully removed from water by 
banana tree adsorbent.

\section{Adsorption experiment of electroplating wastewater}

Heavy metals are main pollutants of electroplating wastewater. Generally, they are treated by restoring, flocculation and precipitation. Due to the existence of reaction equilibrium, heavy metal concentration in wastewater discharged from electroplating factory still exceed the emission standard. Therefore, before this kinds of wastewater discharge into the environment, an additional adsorption operation is necessary in the end of treating process. At present, the most commonly adsorbent used for electroplating wastewater is active carbon. Although active carbon has very high adsorption capacity, it is very expensive. Substitute low-cost agricultural and forest waste adsorbent for active carbon, it not only can reduce cost of treating wastewater, but also can further reduce the concentration of $\mathrm{Cr}(\mathrm{V})$ by reducibility component in adsorbent. In this study, a banana stem adsorbent was used for treating modell electroplating wastewater. $\mathrm{pH}$ of the wastewater was adjusted to about 2 with sulfuric acid. Next, 10L water was suppled by the adsorption separation tube (diameter $=2 \mathrm{~cm}$ and height $=20 \mathrm{~cm}$ ) filled with banana tree adsorbent. Heavy metal concentration of wastewater from the bottom of adsorption column is shown in Table 2.

Table 2 Adsorption experimental results of electroplating wastewater $[\mathrm{mg} / \mathrm{L}]$

\begin{tabular}{lccccccc}
\hline Heavy metal & $\mathrm{Cr}(\mathrm{V})$ & $\mathrm{T}$ tal $\mathrm{Cr}$ & $\mathrm{Pb}$ & $\mathrm{Ni}$ & $\mathrm{Cu}$ & $\mathrm{Zn}$ & Chromaticity \\
\hline Inflow & 1.34 & 2.87 & 0.75 & 0.98 & 1.06 & 3.45 & 34 \\
Outflow(banana stem) & 0.06 & 0.28 & 0.11 & 0.39 & 0.34 & 0.57 & 42 \\
Outflow(active carbon) & 0.104 & 0.37 & 0.14 & 0.36 & 0.23 & 1.08 & 26 \\
Emission limit * & 0.1 & 0.5 & 0.2 & 0.5 & 0.5 & 1.5 & $<40$ \\
\hline
\end{tabular}

*this is emission limit of heavy metal ion concentration in electroplating wastewater in non-Pearl River Delta of Guangdong Province (DB 44/1597-2015).

Because heavy metal concentrations in electroplating wastewater pre-processed are relatively low, no precipitation operation was arranged. Experimental results in Table 2 demonstrated that the banana stem adsorbent can not only adsorb $\mathrm{Cr}$, but also can remove $\mathrm{Pb}, \mathrm{Ni}, \mathrm{Cu}$ and $\mathrm{Zn}$ well. The total removal effect is equal to active carbon. The removal rate of $\mathrm{Cr}(\mathrm{V})$ is significantly greater than that of active carbon. Experiment data revealed that the water volume treated by banana stem adsorbent get about $80 \%$ of that by active carbon at the same adsorption conditions, heavy metal concentration in effluent from banana stem adsorbent is apparently greater than that from active carbon. Since the banana stem adsorbent is far cheaper than active carbon, it still possesses promising economic benefits to substitute banana stem adsorbent for active carbon.

\section{Conclusions}

(1) The adsorption capacity of $\mathrm{Cr}(\mathrm{V})$ of the banana stem absorbent prepared reaches $5.84 \mathrm{mg} / \mathrm{L}$. The appropriate adsorption conditions are $\mathrm{pH}=2 \sim 4$ and $20 \sim 30^{\circ} \mathrm{C}$.

(2) The prepared banana stem absorbent is equivalent to active carbon in term of cleaning of electroplating wastewater. Heavy metal ion concentration in model electroplating wastewater treated with banana stem absorbent can meet the emission requirements of electroplating factory .

\section{References}

[1] D. Liang, X. N. Deng: Chemical Fiber \& Textile Technology No.1 (2007), p28-31.

[2] Y.X. Wang: Earth Science Frontiers Vol.8, No.2(2001), P301-306.

[3] N. Cordeiro, M.N. Belgacem , I.C. Torres: Industrial Crops and Products Vol.19 (2004) p147-154

[4] B.F. Noeline, D.M. Manohar, T.S. Anirudhan: Separation and Purification Technology Vol.45 (2005),p131-140. 